\title{
CORRIGENDUM
}

\section{Sexual activity diminishes male virility in two Coccinella species: consequences for female fertility and progeny development - CORRIGENDUM}

\author{
J.P. Michaud, Mahadev Bista, Geetanjali Mishra \\ and Omkar Singh
}

doi: 10.1017/S0007485313000199, Published by Cambridge University Press, 17 April.

The publisher apologises for an error in the fourth named author of this article. The author's name should be 'Omkar' only, NOT 'Omkar Singh' as published.

\section{Reference}

Michaud, J.P., Mahadev Bista, Geetanjali Mishra and Omkar Singh. Sexual activity diminishes male virility in two Coccinella species: consequences for female fertility and progeny development. Bulletin of Entomological Research. Published by Cambridge University Press, 17 April. doi: 10.1017/S0007485313000199. 